\title{
Oxidative Stress Biomarkers in Urine of Patients with Hepatitis B and C
}

\author{
Ömer Faruk Kökoğlu¹, Hasan Uçmak¹, Ergül Belge Kurutaş², Nurettin Kuzhan¹, Remzi Toprak , Ali Çetinkaya ${ }^{3}$, \\ Bülent Kantarçeken ${ }^{3}$, Filiz Atalay² \\ ${ }^{1}$ Department of Clinical Microbiology and Infectious Diseases, Faculty of Medicine, Kahramanmaraş Sütçü Imam University, Kahramanmaraş, Turkey \\ 2Department of Medical Biochemistry, Faculty of Medicine, Kahramanmaraş Sütçü Imam University, Kahramanmaraş, Turkey \\ ${ }^{3}$ Department of Internal Medicine, Department of Gastroenterology, Faculty of Medicine, Kahramanmaraş Sütçü Imam University, Kahramanmaraş, Turkey
}

\section{ABSTRACT}

Objective: The aim of our study is to determine the role of oxidative stress biomarkers in hepatic damage in hepatitis B virus (HBV) and hepatitis $\mathrm{C}$ virus (HCV)-infected patients.

Materials and Methods: Forty-eight patients with chronic hepatitis B, 15 patients with chronic hepatitis C and 30 healthy individuals as a control group were included in this study. Serum alanine-aminotransferase (ALT) and aspartate aminotransferase (AST) levels, urine oxidative stress biomarkers such as malondialdehyde (MDA) levels, superoxide dismutase (SOD-1) and catalase (CAT) activities were measured.

Results: Urine MDA levels increased in patients with HBV and HCV compared to the control group. It was higher in HCV patients than HBV patients $(p<0.001)$. Besides, while CAT and SOD-1 activities were decreased in the urine of patients with HCV, they increased in the urine of patients with HBV compared to controls $(p<0.05)$. Furthermore, urine CAT ve SOD-1 activities in patients with HBV were statistically significantly higher than those of the HCV patients $(p<0.001)$.

Conclusion: Increase in urine MDA levels in hepatitis forms may be valuable in monitoring in viral hepatitis cases. Also, we thought that insufficiency of antioxidant barrier in patients with HCV may cause oxidative damage, so antioxidant treatment may useful and should be added to the combined therapy for these patients.

Key Words: Urine, oxidative stress, hepatitis B, hepatitis $C$, transaminases

Received: 14.01.2011

Accepted: 23.02 .2011

\section{Introduction}

The free radical, with an unpaired electron, is highly reactive and can damage the cell by peroxidation of phospholipid membranes and oxidation of proteins and DNA, possibly leading to malignant transformation (1). A complex system of neutralizing antioxidants exists in plasma and intra- and extracellular fluids, but an imbalance (oxidative stress) between free radical production and defence can produce cell damage. To prevent destruction caused by oxidative stress, the host uses the antioxidant defense enzymes (2). Antioxidant enzymes such as superoxide dismutase (EC 1.15.1.1, SOD-1) and catalase (EC1.11.1.6, CAT) are closely linked with cellular responses to oxidative stress. SOD-1 (CuZnSOD) is ubiquitously expressed and is a cytosolic scavenger of oxygen free radicals by facilitating the dismutation of oxygen radicals to molecular oxygen and hydrogen peroxide, which in turn is metabolized to harmless water and oxygen by CAT and glutathione peroxidase (GSH-Px). CAT is a heme-containing enzyme, whose subcellular localization is in peroxisomes, and functions in lowering the risk of hydroxyl radical formation from hydrogen peroxide via the Fenton reaction (3). Hepatitis
$C$ virus $(\mathrm{HCV})$ is the main causative agent of chronic viral hepatitis and hepatitis $B$ virus (HBV), is extensively seen throughout the world, and can become highly chronic. However, the pathogenesis of chronic hepatitis is not known fully yet. It has been suggested that HCV and HBV may cause oxidative stress in infected cells. Lipid peroxidation is one of the causes of hepatocyte damage and also increases the level of malondialdehyde (MDA), which is a biomarker of oxidative stress $(4,5)$. Recently, a number of investigators have studied oxidative stress biomarkers levels in serum, plasma and erythrocyte in patients with hepatitis $(6,7)$. To our knowledge, none of the previous research investigated oxidative stress biomarker levels in the urine patients of chronic hepatitis. The present study evaluates the existence of oxidative stress in the urine of patients with HBV and HCV and questions whether the disturbances in antioxidant balance are present in these cases. Also, it was investigated whether there were differences between hepatitis $B$ and hepatitis $C$ patients in antioxidant enzymes and oxidative stress. Also, we aimed to determine the relationship between serum transaminase levels, and urine oxidative stress biomarkers such as SOD-1, CAT and MDA in patients with HBV and HCV. 


\section{Material and Methods}

Forty-eight patients with chronic hepatitis B (CHB) (25 males, 23 females; mean age $[ \pm S D], 36.57 \pm 7.20$ years), 15 patients with chronic hepatitis $\mathrm{C}(\mathrm{CHC})$ (9 males, 6 females; mean age $[ \pm S D], 34.46 \pm 7.65$ years), and 30 healthy individuals as the control group (15 males, 15 females; mean age [ $\pm \mathrm{SD}$, $35.6 \pm 8.0$ years; normal medical histories, physical examinations, blood biochemistry, and negative anti-HCV and $\mathrm{HBsAg}$ ) were included in the present cross-sectional study. Patients were excluded from the study if they had a history of alcohol abuse, other known causes of liver disease (such as metabolic diseases, non-alcoholic steatohepatitis, or any other infectious cause of liver disease), or if the subjects had chronic diseases, such as diabetes mellitus, and cardiac or renal failure. Anti-HCV, HBsAg, anti-HBs and anti-hepatitis B core antigen ( $\mathrm{HBc}$; total and anti-HBc immunoglobulin $\mathrm{M}$ ) were assayed Enhanced Chemiluminescence (VITROS ${ }^{\circledR}$ ECiQ Immunodiagnostic System, Ortho-Clinical Diagnostics, Newjersey, USA). HCV RNA and HBV DNA were investigated using the real-time PCR method (QIAGEN, Rotor-Gene Q, Germantown, USA). Also, alanine aminotransferase (ALT; normal range, 30-65 U/L) and aspartate aminotransferase (AST; normal range, 15-37 U/L) levels were determined by standard automated techniques in $\mathrm{HBV}$ and HCV-infected patients and controls. The spot urine samples of subjects were collected into $75-\mathrm{mL}$ sterile containers (Kayline Plastics, The barton, South Australia, 5031) which were diluted with 1:50 physiologic saline $(0.9 \% \mathrm{NaCl})$ for biochemical analysis and all urine samples were stored at $-70^{\circ} \mathrm{C}$ prior to assay. To control the urine concentration, data were normalized to urine creatinine concentration. Urinary creatinine was measured in spot urine samples by Dade Behring Dimension RXL autoanalyzer (Germany). The study was carried out according to the Guidelines of the Local Ethic Committee of the Faculty of Medicine, Kahramanmaras Sutcu Imam University.

\section{Biochemical Analysis}

SOD-1 activity was measured according to the method described by Fridovich (8). This method employs xanthine and xanthine oxidase to generate superoxide radicals which react with $\mathrm{p}$-iodonitrotetrazolium violet (INT) to form a red formazan dye which was measured at $505 \mathrm{~nm}$. The assay medium consisted of the $0.01 \mathrm{M}$ phosphate buffer, 3-cyclohexylamino-1-propanesulphonicacid (CAPS), buffer solution (50 mM CAPS, 0.94 mM EDTA, saturated $\mathrm{NaOH}$ ) with $\mathrm{pH}$ 10.2, solution of substrate $(0.05 \mathrm{mM}$ xanthine, $0.025 \mathrm{mM}$ INT) and $80 \mathrm{U} / \mathrm{L}$ xanthine oxidase. SOD-1 activity in urine samples was expressed as $\mathrm{U} / \mathrm{mg}$ creatinine.

CAT activities were determined by measuring the decrease in hydrogen peroxide concentration at $230 \mathrm{~nm}$ by the method of Beutler (9). The assay medium consisted of $1 \mathrm{M}$ Tris $\mathrm{HCl}, 5$ $\mathrm{mM} \mathrm{Na} \mathrm{N}_{2}$ EDTA buffer solution ( $\mathrm{pH}$ 8.0), $1 \mathrm{M}$ phosphate buffer solution ( $\mathrm{pH} 7.0$ ), and $10 \mathrm{mM}$ hydrogen peroxide. CAT activity in urine samples was expressed as $\mathrm{U} / \mathrm{mg}$ creatinine.

Urine MDA levels, as an indicator of lipid peroxidation, in the urine samples were determined according to the procedure of Ohkawa et al. (10). The reaction mixture contained $0.1 \mathrm{~mL}$ sample, $0.2 \mathrm{~mL}$ of $8.1 \%$ sodium dodecyl sulphate, 1.5
$\mathrm{mL}$ of $20 \%$ acetic acid and $1.5 \mathrm{~mL}$ of $0.8 \%$ aqueous solution of thiobarbituric acid. The mixture $\mathrm{pH}$ was adjusted to 3.5 and volume was finally made up to $4.0 \mathrm{~mL}$ with distilled water and $5.0 \mathrm{~mL}$ of the mixture of $\mathrm{n}$-butanol and pyridine $(15: 1, \mathrm{v} / \mathrm{v})$ were added. The mixture was shaken vigorously. After centrifugation at $4000 \mathrm{rpm}$ for $10 \mathrm{~min}$, the absorbance of the organic layer was measured at $532 \mathrm{~nm}$. MDA level was expressed as $\mathrm{nmol} / \mathrm{mg}$ creatinine.

\section{Statistical analysis}

In the statistical evaluation of the data, SPSS 13.0 Windows program was used. Results were considered significant at $p<0.05$. In comparison of the groups the One-way ANOVA test was used. Differences between groups were assessed using the Tukey test.

\section{Results}

Serum ALT levels in HCV-infected patients were higher than those of the HBV patients and controls. However, this change was not significant statistically $(p>0.05)$. However, there was no difference in AST levels between HBV and HCV patients $(p>0.05)$ as shown in Figure 1. In the control group, serum AST and ALT levels were found within normal references ranges (Figure 1).

While Urine MDA levels increased in patients with HBV and HCV compared to the control group. It was two-fold higher in HCV patients than HBV patients $(p<0.001)$ as shown in Figure 2.

While CAT and SOD-1 activities were decreased in the urine of patients with $\mathrm{HCV}$, they increased in the urine of patients with HBV compared to controls $(p<0.05)$. Furthermore, urine CAT ve SOD activities in patients with HBV were significantly statistically higher than those of the HCV patients $(p<0.001)$, as shown in Figures 3 and 4.

\section{Discussion}

The protective antioxidant mechanisms are complex and multifactorial. The susceptibility of cells to oxidative stress

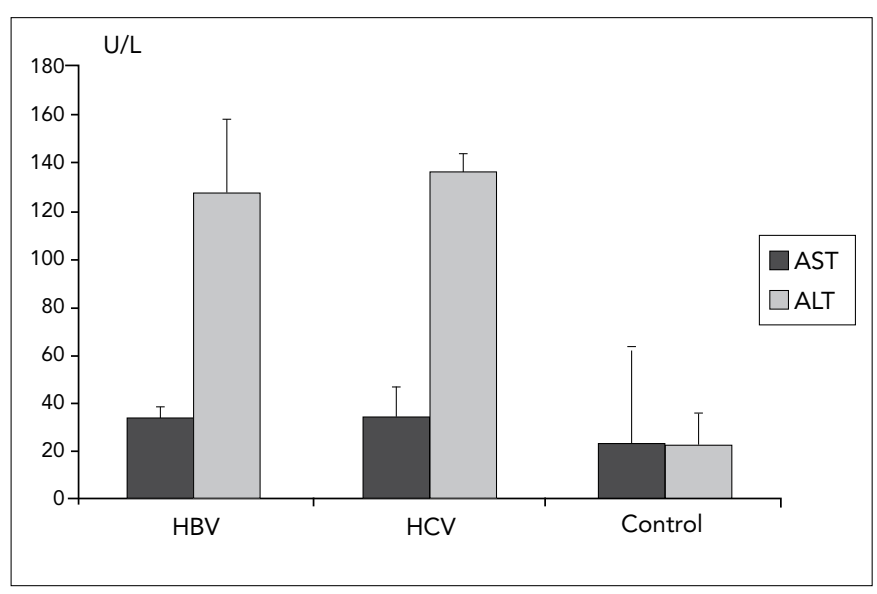

Figure 1. Serum ALT and AST levels in HBV, HCV patients and controls 


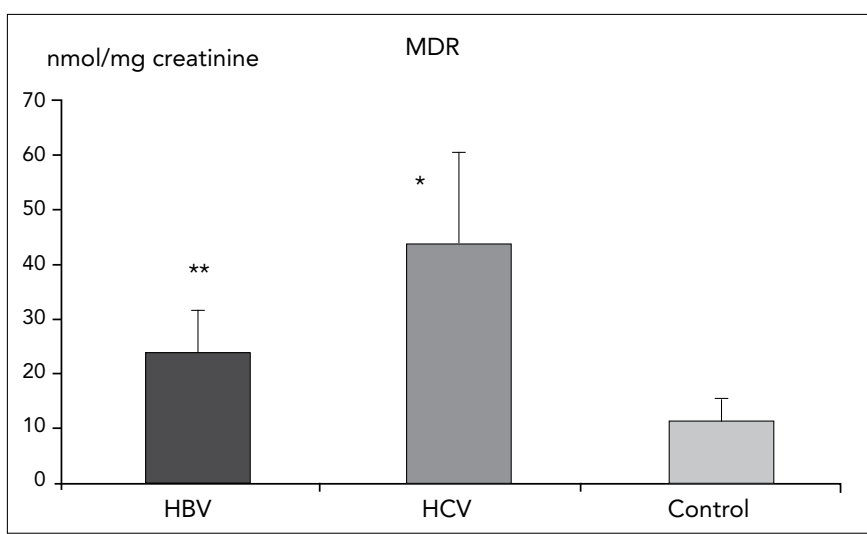

Figure 2. Urine MDA levels in HBV, HCV and control groups ${ }^{*} p<0.05$, difference found statistically significant from control and HBV groups ${ }^{\star \star} p<0.05$, difference found statistically significant from controls

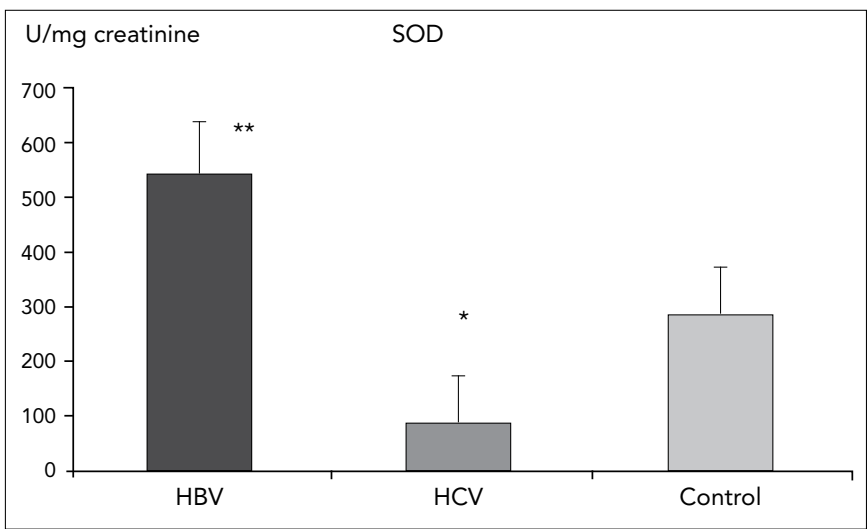

Figure 3. Urine SOD-1 activities in HBV, HCV and control groups

${ }^{*} p<0.05$, difference found statistically significant from control and HBV groups ${ }^{\star *} p<0.05$, difference found statistically significant from controls

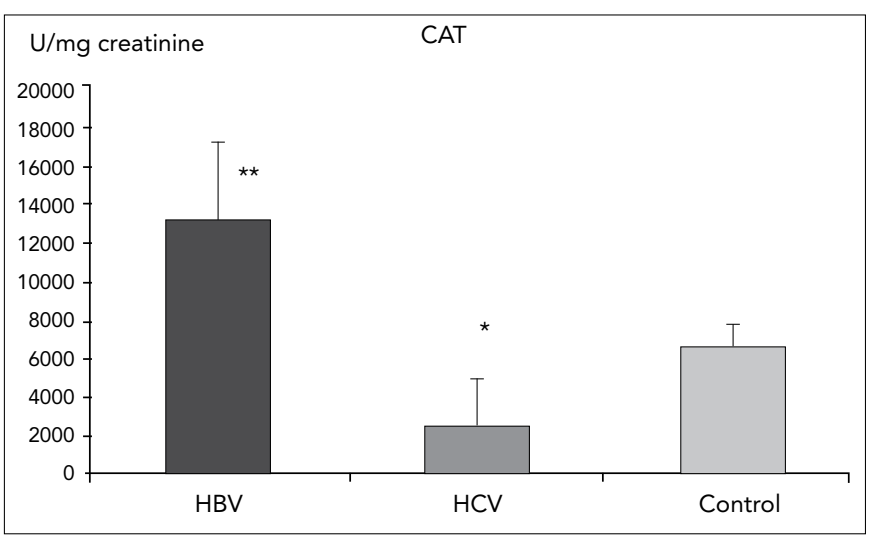

Figure 4. Urine CAT activities in HBV, HCV and control groups ${ }^{*} \mathrm{p}<0.05$, difference found statistically significant from control and HBV groups ${ }^{\star \star} p<0.05$, diffeence found statistically significant from controls

is a function of the overall balance between the degree of oxidative stress and the antioxidant defense capability. Oxidative stress is involved in a number of pathological conditions such as inflammation and cancer and has been detected in almost all clinical and experimental conditions of chronic liver diseases $(4,11)$. Although the main role of immunological mechanisms in the pathogenesis of chronic viral hepatitis
$B$ and $C$ were demonstrated, researchers also concentrate on the problem of oxidative stress in the pathology of the diseases. Ideally, markers of lipid peroxidation and antioxidants should be measured in hepatic tissue (rather than in blood and urine) to reflect the true state of oxidative stress in the liver, but ethical and practical considerations make this very difficult for research purposes. Needle liver biopsy carries a significant risk of morbidity and even mortality and provides very limited amounts of material ( $<5 \mathrm{mg}$ generally). It is impossible, with current techniques, to perform the multiple biochemical estimations which we have carried out in urine on liver biopsy material. As this study was designed to establish a baseline for long term monitoring of oxidative stress in this condition, and since repeated biopsy at short intervals to follow the course of progression or treatment cannot be justified, measurement of urine biomarkers of oxidative stress, interpreted with caution, offers the only practical option at present. There are some studies in the literature that investigated antioxidants and oxidative stress in plasma, serum and erythrocytes, in patients with hepatitis. De Maria et al (12). showed that MDA, a product of polyunsaturated fatty acid peroxidation, was elevated in the liver and blood. Paradis et al. (13) also demonstrated MDA-protein adducts immunohistochemically in infected liver tissue. Boya et al. (14) showed that the peripheral blood mononuclear cells from patients with $\mathrm{CHC}$ had increased MDA concentrations. Romero et al. (15) showed higher serum MDA values in chronic hepatitis $C$ patients than healthy subjects before the interferon treatment. In the present study, we demonstrated that MDA, one of the most reliable markers for lipid peroxidation, was increased in the urine of patients with chronic viral hepatitis in association with serum ALT levels. Increase in urine MDA levels in hepatitis forms may be valuable in monitoring viral hepatitis cases.

Levels of antioxidant enzymes, such as SOD-1 and CAT, are closely linked with cellular responses to various forms of oxidative stress. Chrobot et al. (16) demonstrated that SOD-1 and CAT activities decreased both in groups of children with $\mathrm{CHC}$, and CHB. Loginov et al. (17) studied the antioxidant system in adults with chronic active hepatitis, and demonstrated SOD-1 decrease correlating with the severity of inflammatory process. Ciragil et al. (18) showed that antioxidant enzyme activities (SOD-1, CAT) decreased in the serum of patients with $\mathrm{HCV}$ compared to the control group. A study by Yasuyama et al. (19) showed a decrease of SOD-1 levels in liver tissue of patients with acute, and chronic hepatitis accompanied by fatty degeneration compared with patients with the liver inflammatory diseases of different etiology. In the current study, we demonstrated that CAT and SOD-1 activities are decreased in the urine of patients with chronic hepatitis $C$. The capacities of antioxidant enzymes were decreased in patients with $\mathrm{CHC}$; thereby we thought that there may be oxidative damage in these patients. When the activities of these antioxidant enzymes are insufficient, the organism is not capable of neutralizing excessive ROS, and a hepatocyte lesion occurs as a consequence. It probably decreased the antioxidant barrier efficiency in the $\mathrm{CHC}$ patients studied. The reduction in the amount of SOD-1 and CAT reflects both a decrease in the synthesize capacity of liver, and the antioxidant defense power of 
the patients with $\mathrm{CHC}$. It can be argued that increased lipid peroxidation is caused by the inflammation related to viral infection, and the decreased antioxidant levels may be an early marker of the oxidative stress. Lipid peroxides formed can be chemotactic for the neutrophils causing increased inflammation, which further drives oxidant-mediated injury in the liver (20). The results presented confirm the involvement of the oxidative stress as a part of the pathophysiology of $\mathrm{CHC}$. Thus, our findings support the existence of the oxidative stress in patients with chronic HCV infection and are in agreement with the studies mentioned above.

In several studies, increase in oxidative components or decrease in antioxidants or both have been reported in subjects with either acute or chronic HBV or HCV infection (16, 20-22). Osman et al. (21) reported that an increase in oxidative stress markers (MDA, nitric oxide) and a decrease in antioxidant enzyme activities (SOD-1, GSH and GSH-Px) were observed in the serum of patients with viral hepatitis. Total antioxidant capacity in either acute or chronic HBV infection was measured only in the study of Irshad et al. (11). The remainder used individual antioxidants measurement to assess antioxidant response of the organism. In the same way, simultaneous measurement of the oxidants and antioxidant components of the plasma in CHB infection was performed only in the study of Demirdag et al. (22). The information in the literature about the antioxidant components in subjects with cirrhosis due to HBV infection is limited. Irshad et al. (11) found that total antioxidant capacity of subjects either with cirrhosis due to HBV infection or other liver disease due to viral etiology is either comparable to or higher than controls. Our results showed that urine CAT and SOD-1 were significantly increased in CHB patients, so there may be a response to oxidative stress in patients with $\mathrm{CHB}$.

In conclusion, according to the results of this study, it might be thought that the urine MDA level might be a marker of hepatocellular damage in $\mathrm{CHB}$ and $\mathrm{CHC}$ patients. Also ROS take part in the pathogenesis of $\mathrm{CHC}$ as they decrease antioxidant enzymes activities. Therefore we thought that, in the treatment of chronic hepatitis B and C, antioxidant treatment may useful and should be added to thecombined therapy for these patients. Also, further in-vitro and in-vivo studies are required to clarify the role of antioxidants in HBV disease progression and treatment.

\section{Conflict of Interest}

No conflict of interest was declared by the authors.

\section{References}

1. Halliwell B, Gutteridge JM, Cross CE. Free radicals, antioxidants, and human disease: where are we now? J Lab Clin Med 1992;119:598-620.

2. Sies H. Strategies of antioxidant defences. Eur j Biochem 1993;215:213-9. [CrossRef]
3. Larrea E, Beloqui O, Munos-Navas MA, Civeira MP, Prieto J. Superoxide dismutase in patients with chronic hepatitis $C$ virus infection. Free Radic Biol Med 1998;24:1235-41. [CrossRef]

4. Parola M, Robino G. Oxidative stress related molecules and liver fibrosis. J Hepatol 2001;35:297-306. [CrossRef]

5. Poli G. Pathogenesis of liver fibrosis: role of oxidative stress. Mol Aspects Med 2000;21:49-98. [CrossRef]

6. Broide E, Klinowski E, Koukoulis G, Hadzic N, Portmann B, Baker $A$, et al. Superoxide dismutase activity in children with chronic liver diseases. J Hepathol 2000;32:188-92. [CrossRef]

7. Britton RS, Bacon BR. Role of free radicals in liver diseases and hepatic fibrosis. Hepatogastroenterology 1994;41:343-8.

8. Fridovich I. Superoxide dismutase. Adv Enzymol Relat Areas Mol Biol 1974;41:35-97.

9. Beutler, E. Red Cell Metabolism. A manual of biochemical methods. 2nd edition, Grune and Stratton Inc., New York; 1984.

10. Ohkawa H, Ohishi N, Yagi K. Assay for lipid peroxides in animal tissues by thiobarbituric acid reaction. Anal Biochem 1979;95:351-8. [CrossRef]

11. Irshad M, Chaudhuri PS, Joshi YK. Superoxide dismutase and total anti-oxidant levels in various forms of liver diseases. Hepatol Res 2002;23:178-84. [CrossRef]

12. De Maria N, Colantoni A, Fagiuoli S, Liu G-J, Rogers BK, Farinati $F$, et al. Association between reactive oxygen species and diseaseactivity in chronic hepatitis C. Free Radic Biol Med 1996;21:291-5. [CrossRef]

13. Paradis $V$, Mathurin $P$, Kollinger $M$, Imbert-Bismut $F$, Charlotte $F$, Piton $A$, et al. In situ detection of lipid peroxidation in chronic hepatitis C: correlation with pathological features. J Clin Pathol 1997;50:401-6. [CrossRef]

14. Boya P, de la Peña A, Beloqui O, Larrea E, Conchillo M, Castelruiz $Y$, et al. Antioxidant status and glutathione metabolism in peripheral blood mononuclear cells from patients with chronic hepatitis C. J Hepatol 1999;31:808-14. [CrossRef]

15. Romero MJ, Bosch-Morell F, Romero B, Rodrigo JM, Sera MA, Romero FJ. Serum malondialdehyde: possible use for the clinical management of chronic hepatitis $C$ patients. Free Radic Biol Med 1998;25:993-7. [CrossRef]

16. Chrobot AM, Szaflarska-Szczepanik A, Drewa G. Antioxidant defense in children with chronic viral hepatitis B and C. Med Sci Monit 2000;6:713-8.

17. Loginov AS, Matiushin BN, Tkachev VD. Enzyme system for dismutation of active forms of oxygen in the liver during chronic impairment of the hepatobiliary system. Vopr Med Khim 1991;37:31-3.

18. Ciragil P, Belge Kurutas E, Kokoglu OF, Aral M. Oxidative stress in patients with chronic hepatitis $B$ and $C$. Balkan Med J 2011;28:300-3.

19. Yasuyama T, Inoue K, Kojima T, Sasaki H. Activities, electrophoreticprofiles and immunolocalization of superoxide dismutase in human liver specimens. Jpn J Med 1988;27:34-41. [CrossRef]

20. Dikici I, Mehmetoglu I, Dikici N, Bitirgen M, Kurban S. Investigation of oxidative stress and some antioxidants in patients with acute and chronic viral hepatitis $B$ and the effect of interferontreatment. Clin Biochem 2005;38:1141-4. [CrossRef]

21. Osman HG, Gabr OM, Lotfy S, Gabr S. Serum levels of bcl-2 and cellular oxidative stress in patients with viral hepatitis. Indian J Med Microbiol 2007;25:323-9. [CrossRef]

22. Demirdag K, Yilmaz S, Ozdarendeli A, Ozden M, Kalkan A, Kilic SS. Levels of plasma malondialdehyde and erythrocyte antioxidant enzyme activities in patients with chronic hepatitis B. Hepatogastroenterology 2003;50:766-70. 